\title{
TO THE 70th ANNIVERSARY OF VASYL LENDEL
}

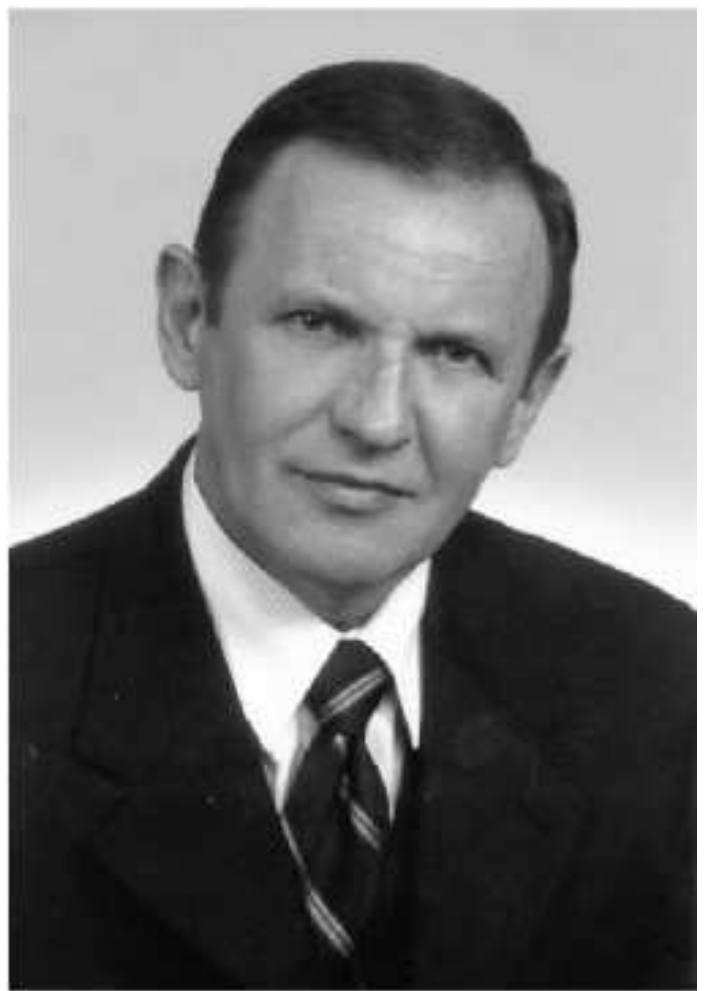

Vasyl Lendel was born on December 3, 1949 in the Volovets of Transcarpathian region. He has completed secondary education in Svalyava, graduating with honors Svalyava Polytechnic College in 1968. He has continued studies at the Faculty of Chemistry of Uzhhorod State University. He has graduated with honors in higher education in 1973.

V.G. Lendel started his work via teaching chemistry at the Svalyava Polytechnic College, and in October 1973 he was invited to take the position of engineer of the Department of Organic Chemistry at UzhSU. In 1974-1977 he studied in graduate school at this department under the supervision of Professor Mygalin Yu.V. In 1977 he has become a head of the laboratories of the Department of Organic Chemistry of Uzhgorod State University.

V.G. Lendel defends his thesis "Reactions of attachment of selenium tetrahalogens to 1,6-, 1,5-, 1,4-diolefins and their derivatives and properties of adducts obtained" and obtains the degree of candidate of chemical sciences in Taras Shevchenko State University of Kyiv in 1981. Later in 1982 he was elected to the position of assistant of the Department of Organic Chemistry, and in 1985 - Associate Professor of the
Department of Organic Chemistry of Uzhhorod State University. He was conferred the academic title of Associate Professor in April 1987. For the cycle of scientific works in 2007 V.G. Lendel was awarded the degree of Doctor of Chemical Sciences.

In June 1996, Vasyl Lendel heads the scientific-pedagogical staff of the Department of Organic Chemistry and is appointed to the position of the Dean of the Faculty of Chemistry of Uzhhorod State University, which he holds to this day.

V.G. Lendel is a highly qualified specialist in the field of organic and element-organic chemistry. He heads a scientific school that studies the synthesis, chemical, physical, and biological properties of chalcogen-containing heterocyclic compounds. V.G. Lendel is studying the regio- and stereo-chemistry of electrophilic intra-molecular cyclization of unsaturated acyclic and heterocyclic compounds under the action of such electrophilic reagents as halogens, chalcogen halides. There are three defended $\mathrm{PhD}$ theses under his supervision; he fulfilled state budget grants and contractual grants, including foreign scientific projects. He has 624 scientific and teaching works, including about 400 publications in professional scientific journals, of which more than 50 publications are in journals included in science-metric databases. A large number of copyright author certificates and patents testify to the practical importance of his scientific research.

He has been awarded the honorary title of "Excellence in Education of Ukraine", "Honored Worker of Higher Education", "Inventor of the USSR", "Honored Worker of Education of Ukraine" for his considerable achievements in work, high professionalism, personal contribution to the development of Ukraine and Transcarpathia. For his merits in scientific and pedagogical work he was awarded the Distinction of President of Ukraine, "Acknowledgment of the President of Ukraine", Anniversary Medal on the occasion of "10th Anniversary of Independence of Ukraine", Honorary Certificate of the Verkhovna Rada of Ukraine, Honorary Certificate of the NAS of Ukraine, Honorary Certificate of the MES of Ukraine, Silver Anniversary Order of the Ukrainian Technological Academy, For Merit industry and art", the honors and thanks of the Transcarpathian Regional State Administration. 